\title{
Challenging Power, Constructing Boundaries, and Confronting Anxieties: Michael Kattirtzi Talks with Andrew Stirling
}

\author{
MiCHAEL KATTIRTZI \\ UNIVERSITY OF EDINBURGH \\ ANDREW STIRLING ${ }^{2}$ \\ UNIVERSITY OF SUSSEX
}

\begin{abstract}
In this interview, Andy Stirling talks to Michael Kattirtzi about what initially drew him to Science and Technology Studies, his account of the impact of the Science Wars on the field, and why it matters that STS researchers do not shy away from challenging incumbents. Through a series of thoughtful reflections on his encounters with STS researchers, Stirling arrives at the conclusion that we should not expect the field to reconcile tensions that are more deeply rooted in society. Nonetheless, he hopes that in the future STS researchers will be more open and admitting of a plurality of epistemic perspectives within the field and avoid overly constraining it-all the while as he continues to demonstrate the value of appreciating such epistemic pluralism to policymakers and stakeholders. A reflection by Michael Kattirtzi follows the interview.
\end{abstract}

\section{Keywords}

interview; Andy Stirling; epistemic diversity; normative commitments; disciplines; reflexivity

\section{First Encounters}

MK Let's start with your own involvement with Science and Technology Studies, and your own sort of background-I know you remember your time in Edinburgh fondly.

AS It was a formative experience for me-one of the most galvanizing of my intellectual life. Actually also my personal life, because it was in the Science Studies Unit (SSU) that I met my partner, Topsy Jewell (who was studying science studies with zoology). But I only had a small exposure to the SSU compared to other people you'll be interviewing, because I was just an undergraduate. I went to Edinburgh to do astrophysics. It was in

${ }^{1}$ Michael Kattirtzi, Email: michael.kattirtzi@ed.ac.uk 2 Andrew Stirling, Email: A.C.Stirling@sussex.ac.uk

Copyright (C) 2018 (Michael Kattirtzi, Andrew Stirling). Licensed under the Creative Commons Attribution Noncommercial No Derivatives (by-nc-nd). Available at estsjournal.org. 
the first year that I took other courses including a science studies introductory course and I also was very interested in archaeology. Then in the second year I got more intensively involved in some of the science studies courses ("science and society" and "social institutions of science," or something)—David Edge, Barry Barnes, a little bit of David Bloor. It was all part of an eye-opening experience that just blew my mind. So I overshot science studies and ended up doing social anthropology, because this seemed to give the broadest context for different ways of seeing knowledge. So my concrete engagement was really those first and second years when I did those SSU courses and got a huge amount out of them. Also following other enthusiasms, I ended up doing a master's thesis in archaeology and social anthropology. Although I didn't do it directly with the SSU, it was a kind of sociology of knowledge: about how understandings of the transition between the Mesolithic and the Neolithic in Europe can be explained by the dynamics of the social communities involved in producing this knowledge. So it was an attempt--a very basic one--to operationalize science studies insights and apply them to archaeology: an attempt to do a sociology of knowledge of prehistory. The thesis did quite well, but went down like a lead balloon in some quarters. But I didn't register very strongly in SSU at all, I was just an undergraduate doing it as a minor. Yet the SSU had a huge effect on me.

MK What happened after that?

AS I had long been a disarmament activist, so after finishing our degrees in 1984, Topsy and I got more into the nonviolent direct action peace movement. I was actually lined up to do a PhD at Edinburgh in social anthropology but ended up heading off in that different way. We were part of the Peace Convoy and the Molesworth Peace Camp: lots of work against cruise missiles and so on. But after a while of that, we got exhausted and went on to work for Greenpeace. Then we both worked for Greenpeace International until 1990 in different countries-until we wanted kids and couldn't imagine both carrying on working with a family in the same intensive way for Greenpeace. So that's when we came back to the UK. Topsy carried on working for Greenpeace International and I thought, where would I like to work in Britain if I'm a Dad and not so immersed in this Greenpeace stuff? I'd been really impressed by SPRU as a place that had done some devastatingly critical work on nuclear, of a kind that we were trying to do on economics-but more effective than the stuff Greenpeace was commissioning and with a much less overtly critical demeanor. So I came to SPRU to learn from people-like Gordon MacKerron initially, but then others-about how you can do that kind of critical political economy. In a way, it was another form of deconstruction of incumbent knowledge. So that's why I came to SPRU, and we've been in Sussex ever since--though I did also do other work for Greenpeace and later joined their Board. Anyhow: that's a potted account of what I was up to. It was the Edinburgh SSU that clued me into a long engagement with STS - and it has ever since been to STS that I owe the single greatest debt in my own work. But I think I do actually have a slightly strange relationship with STS as a discipline, because I am not regarded as a proper STS person by some in the field-- 
perhaps because of my direct engagement with policy. It's kind of interesting, I've got this quite intimate knowledge of (and respect for) various parts of STS-quite intense: but I guess I consider myself more an interdisciplinary researcher than an STS researcher. Of course, STS itself is pretty interdisciplinary. But what I'm a bit nervous about, is the preoccupation in some places with creating a discipline of STS.

MK What's the weakness of that?

AS In my opinion, one of the most important implications from SSK and STS (at least, that I got out of it-perhaps to the consternation of people like Barry Barnes), is that too much domination by disciplines is problematic. He didn't intend to say that, of course. And this is not a kind of caricature Feyerabend position of "a plague on all their houses." It's actually more about the benefits for robust knowledge of challenging power. In a world where there were no disciplines, you would really need them. But in a world where virtually the entirety of academia is locked-in to obdurate disciplinary silos, then what's actually most needed is healthy cross-disciplinary critique-requiring intimate "safe spaces" for substantive interdisciplinary trans-disciplinary challenges. I think the biggest problem in research-and higher education in general (especially social science), is that we are massively too locked in to disciplinary institutions.

MK I see what you mean, but do you think in a sense also, the idea of STS or the structures have enabled you to be an "undisciplined" scholar in that sense?

AS Yeah, I didn't say "undisciplined," I said interdisciplinary. There's a big difference-like between incoherent or multilingual. I don't know if this is what's behind your question, but there is an incredible phenomenon in STS that relates to this: the backlash against radical epistemic pluralism. In particular, many of the key protagonists of the Strong Programme have developed a regressive understanding of what I think is one of the most important fruits of their work, which is the critical strand in STS. For all their enormously important contributions, I'd say Barry Barnes himself is an example of that-and especially Harry Collins, with his agenda around the reinstating of expertise.

MK Barry Barnes?

AS Well, I was very excited quite a few years ago to go down to Exeter, invited by Barry Barnes's unit to give a talk there on my work on the precautionary principle. So I had the very interesting experience of giving a seminar on this and hearing my undergraduate hero Barry Barnes (I couldn't believe it), coming out with the most uninformed, unreflexive and regressive conservatisms concerning precaution-about how it is somehow inherently irrational. I'm afraid both in delivery and content, he sounded like somebody off the US Beltway. It really was quite disturbing. And that was before he learned I'd been at Greenpeace. When he heard that, he launched into the most immoderate caricature of what organizations like Greenpeace are about. We had this ridiculous conversation about the Brent Spar, in which Barry expressed a view of the politics of knowledge that was so simplistic that I was completely taken aback. Having had conversations very happily in my policy work with all sorts of people from BursonMarsteller, from Shell and Exxon, you expect to engage these views. But here I was 
having one of the most starkly unreflexive conversations I have ever had about knowledge and power-with Barry Barnes! I was shocked. I always knew Barry was rightly concerned in his teaching, not to promote a simplistic version of self-conscious "Feyerabendian" rebellion. And he was understandably concerned to clarify that the principle of symmetry is not about that: it's about being rigorous, about being symmetrical. I think he did a great job of instilling that in a really phenomenal pedagogy that he in particular, Barry Barnes, should be credited for. But I guess the Science Wars gave him such an impetus to emphasize that this isn't what the Strong Programme is about, that he simply neglected power in knowledge. But it has nonetheless been kind of odd to hear Harry Collins being much more public in similar kinds of unreflexive terms. Because Barry Barnes has been less public, I failed to realize that he seems to have held even more immoderate views--at least at that stage (it was quite a few years ago now). I've also had occasional discussions with Harry Collins about these issues of power in knowledge. But in that conversation, at least, Barry seemed less open to reflexive consideration of these things. I think it's an understandable emotional thing for people who have always (rightly) been so respectful of science and scientists, and so hurt to see the Science Wars misrepresent what they were about. But it actually wasn't the Strong Programme that was implicated in the Science Wars, but a much more lazy body of thinking elsewhere. But what is more odd is that STS researchers like Harry and Barry did not apply the kinds of nuancing they rightly valued, to their own critiques of the work of critical STS researchers-like Brian Wynne or Alan Irwin or Jerry Ravetz--who actually carried a mature form of this reflexive tradition of analysis into very difficult and even more intensely power-laden policy domains. So this concern is another aspect of my experience of STS--and especially parts of the Edinburgh tradition.

\section{What is "STS"?: Of Disciplines, Boundaries and STS's "Scholars"}

MK So, this interview protocol we've got here assumes that STS is a field but it seems that you don't see it as a field?

AS It is a field. I was arguing about STS as a discipline. First of all it is becoming a discipline but in different ways, in different areas. One is the co-productionist paradigm which is especially prominent in the US, and that's what Sheila Jasanoff in particular is working admirably to develop. Then there's the Actor-Network stuff, which is quite well established around John Law and of course Bruno Latour. Then there's transition studies, which is enormous, and a lot of that holds STS-style inputs and sensibilities, looking more at technology. And so on...So discipline-formation is happening in various ways: STS is not one single thing in this sense. It is more coherent however as an empirical focus of study-on science, technology and society relations as a field. It is because I'm concerned about the epistemic consequences of too much disciplinary closure in academia in general, that I'm worried about STS seeking self-consciously to form its own discipline rather than be part of enabling greater cross-disciplinary interrogation and 
reflexivity. In fact, I think it is a shame-and rather ironic for a community so distinctively interested in reflexivity-for STS to be making so many self-conscious attempts at forming its own epistemic closure.

MK How would you reflect on the origins of the field of science and technology studies, in terms of the congruence of perspectives, conferences, institutions or structures?

AS I'd say the field in general emerged first as a consequence of social movement "murmurations" and collective action-with critical scientists themselves (sometimes Marxist, sometimes constructivist), asking various kinds of difficult questions of established science and technology. So going back to the $70 \mathrm{~s}$, even to the late $60 \mathrm{~s}$ but certainly in the 70s (and especially in the Netherlands), where you had scientists themselves (starting in the tradition of Bernal), becoming increasingly critical of science. British examples include Steven Rose and Hilary Rose-who were beginning to critique the interests at work in shaping the directions taken by science and technology; but who actually held a huge respect for - and a great competence in--processes of science itself. And then as time went on, STS acquired more general kinds of experience, motivations and critique that didn't originate so specifically within the community of practicing scientists. I think this diversification might be an aspect of what Barry Barnes and Harry Collins reacted against, because they regretted forms of STS that were not so rooted and immersed in science itself. I think it's pretty telling, for instance, that Harry in particular is understandably proud at a personal level of the way he was able by the end of his research to participate as a peer with gravitational scientists in discussing their subject matter, even making contributions. So you could say he sort of "went native."

AS STS developed, there emerged a sort of recursively critical echo chamber around the externally critical tradition. There have been a series of episodes of great deliberation within STS and the social studies of science: Langdon Winner and the reaction to his work on artifacts and politics was one; the Science Wars came later on and then more recently Harry Collins' third wave stuff. These "waves" break at intervals because of internal tensions in critiquing a critical tradition. On the part of people like Barry and Harry there's an understandable-but rather self---aim to avoid being seen as critical for its own sake, or to be so too lazily-or unhelpfully to scientific communities they identify with...On the other hand there are other people who've been attracted to the field by exactly the opportunities it affords to substantiate an otherwise seriously lacking challenge to the directions in which incumbent interests are driving science and technology. It's not as if there are discrete phases in this. Harry Collins tells the story as "waves," but I don't think these processes are so much about phases as about successive layerings. There are sediments that accrue, those layering down at later stages without such direct identification with incumbent science, being built on by those laid down at the earliest stages by people like Arie Rip (who were engineers) or Barry Barnes and David Edge (who were scientists). I actually don't think Harry Collins was a scientist originally, but Brian Wynne was. So only after they've got advanced scientific training (in the case of Brian after his doctorate), do they then start doing critical work. So this 
enables STS as it's constituted now, to also involve more people without this. So you've got people like me who did a bit of science but then moved out even before finishing an undergraduate degree-partly because this body of analysis was there to radicalize us at an earlier stage, and partly because the accreditation had to be won first from the incumbency itself. But then you also have an internal reaction to this dynamic. So I think details play differently in different countries. But you've still got these sedimentary layers-all of which are still in play. If you go to Denmark, a large part of STS in Denmark is in the model of Michael Jorgensen, with the tradition of the 1970s science shop still very much alive. To an extent, the same is true of the technology assessment tradition in the Netherlands as well-institutionalized there in the Rathenau Institute. So you've got the earliest levels conditioning these other ones accrued on top. So it's difficult to talk about phases really, there's a constant interplay of tensions. One thing I thought was quite interesting that you might want to look at in this regard, is when Steve Woolgar started at Oxford and ran a series of very illuminating workshops--I went to some of them--called (I think) "STS Means Business." One relevant anecdote from that emerged from the introspection over what it means for STS to now (ostensibly for the first time) be in a management school? Actually STS has already been rolled in to several management schools. SPRU is a recent example. But perhaps it was only because this was an Oxford management school, that anyone really noticed? Anyhow, STS hasn't needed to be in management schools, to have engaged externally for decades. What I thought was quite interesting in this, is that a lot of the great figures in STS--for instance Mike Lynch alongside Steve Woolgar, came along to these workshops to focus on the question, "does this mean that STS is now engaging with policy processes and getting its hands dirty?." The idea behind the workshops (about ten years ago now I think), was that it is only now that STS is "getting its hands dirty." But I think this was more about internal accreditation that a previously reactionary tradition might now engage in a new layering of engagement. I went through all the references of all the elaborate--mostly rather good-papers that had been produced for the workshops, and it was just amazing how little mention was made of STS people like Brian Wynne, Alan Irwin, Jerry Ravetz, Arie Rip, even Sheila Jasanoff, who had been undertaking exactly this "new" style of engagement for decades. There was a sort of sensibility in which a reactionary tradition in STS airbrushed out the people who'd been doing the very thing it was saying it was then about to do. What seemed to be performed here was a kind of disciplining: "STS is now engaging," but on rather different terms and in ways that were in effect denying a history of vigorous external engagement going back to the origins of STS itself in the 70s. It was the wider critical cultural movements that also gave rise to technology assessment that were arguably deeply formative of the opportunity for STS to form its earliest layers in the early 70s. So that made me realize that layered over this was a vision of STS on the part of figures like Mike Lynch and Steve Woolgar, centered around laboratory studies located in universities; with a particular concern for pedagogy and the disciplinary destiny of STS. Under this view, all those guys who went off and engaged critically with 
policy became irrelevant, because they thereby disappeared off the radar of social studies narrowly of science itself. But STS moving in a self-identified way into an elite university like Oxford, gave legitimation in those narrow core terms for what was an old pattern. For those with interests in narrow disciplinary status and attached academic prestige within higher education, Oxford is a seductive place for STS to be able to go. And so prospects of recognition by Oxford suddenly gave STS in this tradition, license to accredit external engagement. But this was, crucially, not in the same critical tradition of previous layers of engagement, but in a more instrumental management mode. All this made me realize without any disrespect to any of the inspirational individuals mentioned, that there's an introspective tradition in STS more widely, which is just concerned with STS itself in an almost solipsistic way: endlessly pouring over itself and forgetting all sorts of things to do with its past engagements in the outside world. I've not really seen this reflected on properly.

MK What counts as a valid STS study, I suppose. Or "scholar."

AS Yes, the term "scholar" is often used in that discourse. "Scholar." It's kind of interesting because it's a very archaic term, which would contain all sorts of meanings that are kind of interesting. You know, not "researcher" but "scholar." What does it mean to say that? It's insisting on a rather paradoxical sense of the detachment of knowledge, which is precisely the idea that STS-in all traditions--has so effectively (and so rightly) critiqued. I'm relishing the irony, but it's not accidental: it's part of the reflexive layering dynamic. Mike Lynch has done brilliant work around this--I don't know if you're talking to him?

MK I'm personally not, I don't know who's being interviewed for this project.

AS Anyway, it would be great to hear him reflect on these things. One of the terms which bears on this dynamic is "reflexivity," on which his stuff about ten years ago was just fantastic. So he's implicated in the kind of dynamic I'm talking about, but certainly not unknowingly: perhaps he's just deliberately decided to focus on this more "scholarly" introspective idea of what STS is and what it does.

MK I think there's potentially a point about to what extent can reflexivity be done on the inside.

AS Quite. One of the lessons I've learned indirectly from STS is about reflexivity. But it's not a located quality (as much work in STS continues to imply): it's a distributed dynamic. In some ways, I thought Mike Lynch's paper on reflexivity pointed this out very well—but in the end he didn't quite deliver on this. He still seemed to talk about it as if the question is: "what can we do to achieve this quality?" Whereas to me the crucial insight in STS is to see social reflexivity in a much more inchoate way as a distributed relational process, which arises not from fostering particular internal disciplinary qualities, but from incommensurable buttings up with disparate external things. But then this would mean that STS cannot achieve this cherished (often claimed) quality, by being concerned to develop a particular pedagogy or doctrinal canon. To seek reflexivity in a particular body of scholarship seems self-evidently self-contradictory to me. 


\section{Inflexions and Instruments}

MK I guess we're talking here about some of your frustrations with the direction that STS has gone in.

AS You're right that it comes over that way, I don't mean to convey that, though, because: first of all, I've said my own debt to STS—and to many individuals within it--is far greater than to any other field. Secondly, STS remains vigorously recalcitrant despite all these self-conscious efforts to form this single scholarly discipline. It remains a vibrant arena for interplay of different disciplinary influences, which thankfully still strongly resists these doctrinal pressures. So I think STS remains really healthy despite itself.

MK It's perfectly legitimate to be both frustrated and see the positives, I can see that you are very proud of the STS tradition.

AS Yes, I am, I'm very affectionate towards it, I owe a big debt.

MK What have you found particularly compelling? Particularly thinking about any foundational works or "turns" - the reflexivity turn, other turns in STS, key topics and concepts?

AS I've talked about reflexivity. I think STS has come up with quite a few potent tools and methods in this regard. As a good STS citizen, I baulk at the word "tool." But the term can be used not only of any means, but also of any ends. So, for achieving in more distributed and relational ways, critical or reflexive thinking about power and knowledge, I think tools can be incredibly important. Here, vocabularies themselves can be a tool-having words for things that incumbency finds it inconvenient even to name. "Reflexivity" itself is just such a word. So that's what I find compelling about STS. It's a messy, sticky body of practice which consistently generates all kinds of useful resources for people on the edges and outside, who wish to challenge power-in-knowledge. The danger is that a norm of stepping outside boxes itself becomes a box, leading STS to get recursively locked into itself. The price of satisfactorily distancing in one way, is that the means to do this can become quite self-referential in other ways. So in order to properly articulate the concerns of STS it seems necessary for STS to isolate itself and just deal with these internally because otherwise engagement is experienced as an intellectual compromise. So I sometimes find my own work, then--and the work of people I especially respect, like Brian Wynne I've mentioned, or Sheila Jasanoff-sometimes frowned upon because external engagement sullies internal identity. For instance, Sheila Jasanoff has worked really effectively in the policy interface. Most of her work is of the highly reflexive kind I mentioned. And she is rightly very concerned about instrumentalizing of STS. But in some ways this can miss the kind of point I'm trying to make. For instance: diagrams. I like to use diagrams to try to articulate ideas. STS has long used diagrams in all kinds of ways. But Sheila herself is sometimes quite concerned about this particular means of expression, as if it is essentially instrumentalizing in its own right. So, the co-productionist school, especially in the US, tends (at least implicitly) to the view that the only really authentic way of articulating the STS sensibility is in a narrative form. Of course, this plays to particular skills--which Sheila, for instance, has 
in abundance. In this view, using graphics can be seen as intrinsically compromising. But I think instrumentalization can be as relevant to narrative as to graphical expression-and reflexivity should not be seen essentially as an inherent attribute of either. There's a contradiction in what I've said because I'm emphasizing again how much I value some of the products to come out of STS, but also making criticisms. Of course, it remains true to an extent that you don't get to achieve those kinds of nicely honed moves unless you have spent a lot of time deliberating over them. On the other hand, I'm impatient with such moves being seen as ends in themselves. So all this is trying to answer your question about, what do I really value. Do you want me to be more specific?

MK Perhaps yes, and maybe some foundational work--you mentioned power and reflexivity.

AS Foundational work? I think this would include "boundary objects," "co-production," "framing," "interpretive flexibility," "the symmetry principle," "reflexivity" itself. All those and the names attached would be examples of vocabularies-as-tools that I think can be fantastically powerful. And then beyond this, there are more specific moves, like Jerry Ravetz's stuff going way back, or Brian Wynne's distinction between different kinds of uncertainties. These move out of processes of interpretation and understanding alone and themselves become modes of action: they create interventions in their own right, that enable great use of the wider work we were talking about earlier. Then you have more recent things-in terms of the turns, you've got successive turns to: reflexivity, ontology, materiality. And of course none of those "turns" are in fact set-piece moves by STS as a whole. As with "waves," they are labeling longitudinal things as horizontal things: the churn in continuous traditions that have always been and relate closely to one another, simply rise and fall from ascendency in some moment or view, because some charismatic paper or person is getting a lot of attention at that point. Then they get called a "turn." For instance, there is the materiality stuff-as Noortje Marres has written about? I have huge respect for her and I enjoy and feel rewarded in trying to engage with this work, but in the end I fear that as a self-conscious "turn," it might become quite self-referential. It makes sense mostly with respect to interest confined specifically within STS. At one level, it implies STS should not just be about epistemology but (as if directly) about ontology-about "what there is in the world." This allowed STS to say it's respectful of materiality in ways it has been accused of not being in the past. So it was a double move. It was a sort of expedient way of defusing a type of Science Wars related critique by responding that: by engaging with ontology we're more respectful of materiality as it exists. But this is at the same time making a greater claim of exactly the controversial kind we made before: an arguably more radical, more critical claim about the scope and depth of STS analysis. It's like trying to have its cake and eat it. Very clever. I think it is performing this double move very--but it does so at the expense of the kind of vocabulary and mode of discussion that can become so arcane that most people wouldn't be able to follow what was happening. So in defending against outside pressures, STS can descend more into talking only to itself. The earlier moves I mentioned are ways in 
which STS can engage with the outside world in quite fruitful ways. "Reflexivity," "framing," "interpretive flexibility"--they're not entire bodies of relational constructs all dependent on each other; they're little heuristics that can be thrown out and have catalytic effects. But the other things (like the co-productionist or actor network paradigms) are entire frameworks that require one to accommodate a broader, more structured, array of concepts and relations and categories.

MK I guess those are particularly compelling and the other slightly frustrating. Let's come back to Edinburgh.

AS I already did say it was formative for me personally. And of course Edinburgh right back to the 70s has also been continuously formative more widely. To take Donald MacKenzie, for instance, I think his body of work is just stunning. I don't know Donald MacKenzie well, I don't even know his work as well as I should. But what I think he's managed to achieve is amazing. The old work on cruise missile guidance and the more recent stuff on finance is extraordinary in several ways-both the content and the kinds of skills it embodies. I think it was amazing to penetrate those very prestigious privileged communities with such ostensibly threatening associations (like being a CND member investigating USAF cruise missile guidance systems) or such overtly challenging agendas (like looking at procedures around derivatives right at the time when there was such political pressure). And to pull off this kind of rich critical analysis in ways that the community concerned so obviously respects, is quite an achievement. Then you've got Robin Williams's stuff, which I think is also really great. It's more in the style I mentioned of SPRU, in some ways. It's interdisciplinary, it's across different faculties, it engages in policy, it is sometimes substantively critical work. Of course, Innogen also does some highly instrumental work on innovation--aligned with the interests of incumbents: for instance by Joyce Tait. But I actually value this pluralism. SPRU too is not only interdisciplinary but politically pluralistic. So what I like about SPRU is that it often has working in it people whose work is aligned with completely opposite sides of a given policy debate, and that's very unusual. The Lancaster STS group, for instance, has long been a fantastic research center from which I've learned a huge amount-especially from Brian. But it didn't tend to span the political as well as disciplinary divides in quite the way Edinburgh has, in the form not just of Innogen but going back before. So I think that's quite a precious characteristic for Edinburgh to have sustained--and in times when (if you think about it) STS groups around the country have folded into management schools... and then often later died. There's been this pattern in Aston, Bath, Brunel, Manchester, Steve Woolgar I've mentioned at Saï-SPRU has been put in the management school and Innogen is also much more in a management school mode. The suppleness of political pluralism is a necessity under these kinds of pressures. 


\section{A Loss of Nerve in the Field}

MK There's a related question here-like all academic fields STS has been shaped by underlying political commitments and concerns, and what do you think have been the most significant?

AS The ones I've mentioned: the early formative Marxist critique of interests in science; the broader critical perspectives on power-in-knowledge; the more specific critiques of particular business or government interests in the direction of research and innovation (the sort of thing I attempt myself). But also what's been formative in STS has been a reaction to this, which I also talked about in relation to experienced people like Barry Barnes or Harry Collins, who've reacted to this and become prone to defining STS and research quality in antagonism to this tradition. I think the so-called Science Wars were really damaging in instilling a kind of loss of nerve on the part of some areas of STS.

MK Do you think that still affects the field?

AS Yes, I do. But I think that was bound to happen in some way or other, because there is so much lazy appropriation and superficial adoption of vocabularies that it was, in a way, an accident waiting to happen. Interestingly, the impact was actually quite peripheral to STS. The main target for criticism was not STS. So, in being as cowed as it has, I think STS has been a little bit unreflective. It's the job of STS to interrogate the dynamics of knowledge. And if you're doing the job of interrogating power-in-knowledge, then you can expect this whatever you do. There's no need to become anxious about high-profile attacks as a problem in their own right. This is true of all kinds of power. As arguably the single most important social process, power (whatever we call it), is about asymmetrically structuring agency. So power by any name (or in whatever terms) isn't of itself necessarily a focus of STS (and I think people like Barry Barnes would say it's not). But nonetheless, once you start interrogating the social dynamics of knowledge, then power (in all its various complicated forms) is one of the most important things going on. So any discipline concerned with interrogation of the dynamics of knowledge, is going to find itself constantly on the receiving end of exactly this kind of dynamic, you should expect it. Indeed, if it doesn't do this, it's not doing its job. So being reflective about the positioning of STS in the wider political economy, means recognizing that there isn't anyone else concerned so centrally with doing this job on knowledge. This role is precious to wider society, because knowledge itself is such a diagnostic feature of the dominant Enlightenment culture of Modernity. The more central the object, the more crucial the interrogation. Ironically given this centrality, Modernity cannot know knowledge for what it is. We cannot, as did Jesuits, recognize the social value of knowledge as a resource irrespective of it's veracity. Where an Enlightenment culture holds that knowledge "comes from nature"--from the discovering of stuff-then it's especially threatening in a modernistic tradition to be doing what STS does. So why do some STS researchers get so surprised and anxious when it is attacked, and agonize about what we can do better? STS made itself vulnerable by being STS. So, I lament the loss of nerve that's taken place, of all kinds: whether it be retreating back into, "oh lets 
just do our thing in a narrow SSK tradition"; or whether it's overtly going on the warpath like Harry Collins and trying to reorient a whole program to reinstate a respect for expertise as an end in itself, because we've supposedly gone too far in a critical mode; or whether it's Steve Woolgar in the early days in Saïd, effectively saying "let's join the establishment on whatever terms we can work out." This may also be relevant to negotiating the process of becoming a discipline-in the way that Sheila Jasanoff (for instance) is doing so determinedly--and in many ways so admirably. To set up a canonical body of doctrine and pedagogy can make a vulnerable community more resistant to this kind of outside pressure. But where power-in-knowledge is the main part of the focus, then this can also become a danger. Seeking to avoid this kind of backlash can become a source of vulnerability in its own right. It is inherent to the essential provocation of STS, that it will always be labeled as flaky, self-indulgent and critical-forits-own sake. These are indeed vices. But no amount of rigor will forestall the accusations. Even the most robust STS will always get this kind of stuff thrown at it, because of what it does. If it aims to avoid this, too exclusive a focus on disciplinebuilding--especially in elite institutions--can pay a heavy price.

MK That's interesting, that's a really profound insight.

AS Do you think so? Oh thank you!

MK Related to the sort of politics of the field (and you're very open about your personal politics), what would you say is your personal politics in STS?

AS I would say in general: challenging power. And in STS: challenging power-inknowledge. Not in set-piece disciplinary trenches, but in murmurations of many small "judo" moves. I've always been motivated to do this. Power is not necessarily a bad thing, but is most likely so, if not challenged. Of course I don't do this gratuitously, I'll choose the arena. Like, I don't do it on climate change. Maybe I should, but I don't because I'm worried about what the wider effects will be of this. So yes, I think I've said enough about my political orientations.

\section{Positioning STS in a Broader Landscape}

MK You have reflected earlier about the positioning of STS in broader disciplinary institutional and political landscapes. Is there anything you'd like to add in terms of thinking about academic fields, publics, institutions or policymakers?

AS I think there's an interesting issue around Geography. I don't know if anyone's raised this, but a failure by STS to engage properly with its interdisciplinary potential may, I think, have left more space for Geography, which has arguably been picked up very well by people like Sarah Whatmore. So there is quite an important body of work in Geography which is basically applying STS concepts, but through the latitude of their own vocabularies like scale and space (which are fantastically malleable metaphors). So they've picked up the challenge and are often doing quite an interesting job in areas where STS hasn't really touched but might have done. Maybe this is even the best way 
for this to happen, because Geography's already a high status discipline that has a license to study everyone else because it hasn't got a topic any more-and it has also got some great heuristic frameworks for this. I think for anyone telling a story of STS in the way your question suggests you're interested in doing in this book; thinking about Geography is quite important because it's the most important single part of the landscape outside STS that bears on the destiny of STS. I'm talking here about important things in the landscape around STS-you asked for other things: what were the other things?

MK Just the idea of STS in relation to other disciplines, other institutions, and the political landscape?

AS This is me banging the drum for the kind of thing I think it's interesting to work on, but you'll get a lot of that I suppose? So I think the power dynamics around disciplinarity are something that STS missed a trick by not looking at more. I think it's enormously important as you get these new globalizing initiatives: with the whole Anthropocene "planetary boundaries" analysis, and the integrated assessments going on on every subject, the global orders around innovation itself being recognized as an organizing principle (continuingly central in European Union, UK, US and Chinese policy, for instance). In all these ways and more, totalizing views of science and technology are becoming elevated to ordering principles for society in general. So the stakes are high not just around science and technology per se, but also our understandings of them. "Responsible innovation," "innovation union," "evidence-based policy," "global assessment" and the whole Anthropocene "planetary management" all exemplify an incipient radically newly intensified form of governmentality around how humans might engage in an ostensibly singular standardized world: to control it. They depend on particular ways of conceiving and ordering knowledges. So what's needed to challenge this are radical forms of diversity and conditionality that rely much more on overtly interdisciplinary and trans-disciplinary perspectives, than on any single disciplinary insight. The medium is the message. There's things going on here about the terms of trade between disciplines which are really interesting and require a focus intermediate between the narrow laboratory studies of SSK, and the critical tradition of policy work on set-piece issues like nuclear or GM crops or whatever it is. I think that this middle ground is crucial and there's not really enough self-reflective work in STS going on around it. In Edinburgh, though, Catherine Lyall in Innogen is doing some great stuff on this - and there are, of course, other people working on it. SSK vocabularies like ActorNetwork are around either the laboratory dynamics, the network dynamics of interpersonal networks and texts produced in particular settings, or STS is more expansively critical looking out in the Brian Wynne sense of looking at policy processes, in nuclear and GM and that kind of thing, and also what Sheila's looked at. But then there's an intermediate Peter Galison thing about the dynamics of disciplines, bigger than networks of researchers in particular settings but smaller than science out there in 
society, about the terms of trade intermediately. It's here, we're talking about STS itself and its propensity to in certain guises try and form a discipline, that level of dynamic.

MK I wonder if you could give an example?

AS Responsibility or ethics frameworks, or integrated assessments would be examples. What DEFRA [the Department for Environment, Food and Rural Affairs] thinks it wants are things like the national ecosystem assessment, which is a big multidisciplinary structure yielding values for particular qualities in the environment or by implication also for different strategies we might undertake policies then you can do a calculus to work out which yields the optimum value by reference to this ecosystem assessment.

MK Yes, so it's also frameworks.

AS Great big set-piece structured frameworks ordering different disciplines, other inputs so you've got, constructivist social science can come in here, it can be in the diagram but you've also got the ecologists doing their thing, unperturbed by this because they're all organized where it integrates them. It's all been disciplined in the literal sense of the term, and STS is allowing itself to be accommodated to this kind of thing I think. I'm kind of interested in what the terms of trade are, just exposing the different ways in which knowledges themselves can be articulated.

MK Just reflecting on your own work, and core groups in terms of the disciplines, the broader disciplinary institutional political landscape, core groups in those landscapes, how have they been important for your work?

AS I conceive myself as interdisciplinary. A lot of STS is keen to differentiate itself, whatever school it comes from: co-productionist, Actor-Network, whatever--keen to differentiate itself from others. Whereas in my time I've got into things like evolutionary economics, institutional economics, various forms of political theory, ecological economics, and found so many resonances, different vocabularies. For instance, one of the things I've been interested in is evolutionary economics, how a lot of that language is very amenable to being used in conjunction with STS sensibilities, even though they're positivists. So with notions of lock-in: in a way you could say what STS is about is "epistemic lock-in." We don't use that language, we could do. Even the evolutionary ontology is itself suspect in STS but I think it can actually be quite useful. So I've been interested in making links between these things and then most recently development studies with the STEPS Centre, which I've been a co-director of. For ten years we've been working on what are called pathways, it's an attempt to arrange a bunch of insights we owe to STS principally, and political ecology, into a form that can be used by practitioners and activists in, especially in developing countries, addressing some of the things that STS tries to get to grips with but outside the usual northern heartlands of STS, other places where STS doesn't often reach. The STEPS Centre is only one of the things I do but I find it really rewarding. But you don't get seen as being part of STS. I get invited to conferences a lot, and it's true to say that with the exception of splinter groups like S.NET-a community of STS researchers strongly engaged on emerging technologies-I have never been asked to give a talk to a full STS conference. I've given something like 600 talks in 20-something 
years, so I'm always giving talks and I'm giving talks to a number of disciplines, geographers, economists, risk assessors, innovation studies, conferences, on those topics, but usually not STS, even though I consider myself as most influenced by STS.

MK That's very interesting. Do you feel marginalized from some aspects of the STS community?

AS On occasion, I'm quite explicitly marginalized. I've been told, for instance: “I can't really engage with you because you are not actually interested in building the discipline that I'm interested in building." What's been interesting is, this work, you think it's not being noticed and then you find, like the manifesto (we did a manifesto for the STEPS Centre)-a manifesto on innovation in sustainable development--we won a prize from the EASST, then we did another thing that won an EASST prize as well. So collaborative things that we've done together with partners have got generous recognition so I'm not complaining. I think we've had some nice acknowledgement and we get a lot of appreciation so it's not been marginalized in that sense. But it's a strange move whereby you are not the core business of STS, even in EASST_-but especially 4S--is developing this canonical introspective thing. It's not like the people are preoccupied with that, that's just what they do when they're engaging in that mode. So it's a different mode, when STS is "performing itself" it doesn't get concerned with the external-facing work, but when it's looking at the outside world then it does see this...I think it's that's a sign of a community that's a bit schizophrenic, a bit unsure of its identity--verging on the solipsistic sometimes, too preoccupied with itself, not self-confident about where it is in the world and why.

MK Do you think that's reconcilable?

AS Maybe it's not actually. I would have said prior to this conversation, yes, but then there's actually the thing you've elicited from me about why it shouldn't be surprised that it gets these tensions. In a way it's a function of the position it finds itself in: so in a way it's not reconcilable-because if it were reconciled it would mean that STS could somehow accommodate tensions which it is not in its gift to actually change. So that would be a bad sign because one would think: how has it done that? It must have made a move in some sort of state of denial where you don't see the pressures anymore. So actually, probably not, probably you should celebrate it. Maybe we could talk about it a bit more explicitly to one another, though.

\section{Talking STS in the Future: What Next?}

MK That comes on to the future of STS.

AS Do you mean normatively or predictively?

MK Where should it be going or where do you think it is going? Let's start with a description and follow through with it.

AS Although normally people do the former by means of the latter, don't they?

MK (Laughs), Yes, but if you can do that as reflexively as you can. 
AS I fear it's going down a more disciplinary route, under which it will fail to give rise to the kind of interdisciplinary space that I think it could... I think STS has all the tools and sensibilities and practices and culture necessary to look afresh at disciplines and think we need to change the way we organize knowledge and organize pedagogy and organize higher education research. But actually the terms of trade can be questioned and that means to think about interdisciplinarity and multidisciplinarity, different modalities, there is no one pristine way to do it but there are different ways in which disciplines as we now call them can engage with each other. So STS is very well placed to do that, but isn't doing it enough. It's more concerned about itself becoming a discipline. So rather than interrogating the entire notion of a discipline and how it relates to other disciplines, it's more accepting that uncritically, and I think that's a failure of imagination because researchers have been spending so much time looking for tenure (which is especially pronounced in the US), and that means disciplines, if you don't have departments you're dead as a researcher, so they don't think about the effect of having departments, they think we need departments. So they're thinking in an instrumental uncritical fashion about the mode of organization of STS, and for me that's an abrogation of responsibility and of the tradition of STS which is one of, never mind a critical thing but just interrogating knowledge itself, turning it into something of interest to be interrogated, and that's not being questioned. It could be probably that both will happen. As STS does this, then it will also manage to accrue more of its own self-interrogation. So I think it will be trying to form a disciplinary program (or actually several different ones), and there will be some fissioning happening, and that process will engender the kind of critical thing I'm talking about as well, so both will be going on. I suspect that will be part of the story of STS but also it's going to suffer pressures like those that anthropology is facing for instance about the "embedded" formula. And I think STS whether it be moving into marketing or mission-oriented agencies, the Netherlands have pioneered it with Rathenau and RIVM especially in environment, we need STS to give us more robust interrogation of uncertainty.

MK What excited you most about STS, and I guess what excites you about where it seems to be going?

AS To go back to the 80s in Edinburgh, what excited me most is the idea that social processes of knowledge themselves can be a subject of scrutiny. And the implications are profound for the directions of progress. This still excites me because, even though it's familiar to oneself, in society at large it's not a familiar thing at all and so you constantly have the experience of trying to explain the implications of that to people who haven't really thought about it. I was just doing so today on a conference call to people on a project and they'll react, they'll get cross, they'll think you're just waffling and then there will be this thing. At the end of this conference call today for instance, the guy who'd been fiercely defending what he wanted to do, he said, "no, I'd like to do it that way, I'd like to do it that way!" And it was simply just by trying to explain what STS has basically been studying, in this case an environmental analyst, he just got it and then was willing to 
change something, they've not got very long to do this and wanting to change it. So I find that exciting, just to be someone who, through no merit of my own--just being positioned and networked to help to do that. And the fact that there are very powerful forces (not least, ones in DEFRA) trying to suppress this all the time: provide disincentives to do it (because there are huge incentives for not doing this). But this is actually a project for DEFRA and everyone's invoking DEFRA, "they don't want that," and they're right they don't want it. So that's a real privilege really to be put in that position by STS and able to take this tradition and apply it. That's what I most enjoy about STS: it's sort of given me a license to do work I really feel very motivated by and committed to.

\title{
"Talking STS": Different Things to Different People?
}

\author{
BY MiCHAEL KATTIRTZI
}

What does it mean to be talking STS? During my PhD studies I found Andrew Stirling to be one of the most inspiring STS researchers to read and to talk to. Amongst his multiple contributions are innovative methodologies for participatory governance (Stirling and Mayer 1999, 12) and novel ways to think about decision making under different "degrees of incertitude" (Stirling 2006, 239). He is, moreover, known for astutely interrogating expert advice to government "in real-time" in the many advisory committees and events in which he has been involved.

For these reasons I consider Stirling to be a central STS figure, and I wanted to use the interview to explore what it means to him to be working in this field. The interview took us both on an exciting and surprising journey bringing to light the implications of observing STS through one of many STS lenses. Here, I reflect on two areas of disagreement that Stirling discussed in the interview: contestations over the role of political commitments in STS, and the dangers of "siloing" the field into a narrowly conceived discipline.

\section{Contestations over Commitments}

Stirling is open about his political commitments. He has worked for the peace movement and as an environmental activist. His move into academia has enabled him to examine relations between science, government, and its stakeholders in a range of policy areas. He is critical of the ways in which influential political actors selectively invoke scientific evidence to support their preferred policy outcomes--for instance, for genetically modified crops and nuclear energy generation. He has an explicit agenda to expose and to challenge powerful actors' instrumental uses of expertise 
to legitimize decisions. While he is by no means the only researcher to apply STS concepts in this way, his commitment to this agenda is interpreted by others in the field as too radical. Here, I attempt to reflect on this contestation symmetrically, (at least as an aspiration (Collins 1996)).

In our interview, Stirling responds to the charge that his approach is too radical by arguing that his critics (who include Harry Collins and Barry Barnes, who first introduced him to science studies) betray the radical implications of their own work. He attributes their positions to an emotional "loss of nerve" following the Science Wars. He goes on to say that his detractors lack a particular form of reflexivity: in making the world conform to specific methods, inscriptions, and references, we risk excluding alternative ways of making sense of the world-and becoming less open to learning from those who see the world differently than we do (Stirling 2006, 248).

Intrigued to consider how his critics might respond, I find that Collins does acknowledge the Science Wars as a turning point in his work: writing with Rob Evans, he explains that third wave studies were in part motivated by "political and academic unease with the existing situation in science studies" (Collins and Evans 2002, 237). ${ }^{3}$ Against this backdrop, the authors then move on to reopen a question that Stirling and others in STS deem ill-fated (e.g. Yearley 2005), namely: "what makes science special?" (Collins and Evans 2002, 242).

It is clear to see why Stirling attributes Collins and Evans's position to a loss of nerve. It is not the normative agenda per se that troubles Stirling, but that this agenda seems to have motivated the authors to put old wine in new bottles. While I do not expect third wave studies to yield a meaningful answer to the question above, the history of science is replete with cases where nascent paradigms emerge with inconsistencies and problems (Kuhn 1960). Even if the core aim is futile, the line of enquiry can give rise to meaningful ideas. In particular, I consider Collins and Evans's concepts of interactional and contributory expertise (Collins and Evans 2002, 254) to be novel contributions to STS-although the concepts remain problematic in that the analyst will struggle to define the boundaries of many fields without implicitly siding with specific actors' contested conception of who the experts are in that field (Gilbert and Mulkay 1984, 120). For instance, once could make a strong argument that specific STS experts such as Andrew Stirling have more "contributory expertise" than some natural scientists in the field of science advice--not least because of their attentiveness to uncertainty and the roles and concerns of citizens--but definitions of the field of science advice, and the list of experts in that field are both open to interpretation.

I feel discomfort with the ad hominem nature that debates about third wave studies often take. It is clear that political and epistemic differences contribute to the disagreements. By distinguishing the "context of discovery" from the "context of justification" (Popper 1959, 31)-and acknowledging that the former have a role in shaping the latter for both positions-I encourage the field to allow for both perspectives to legitimately be explored within STS.

${ }^{3}$ Collins has also written on the Science Wars (Collins 2006), and Simon Jay Lock's PhD thesis includes a gripping chapter on Collins's efforts to protect STS from natural scientists' reactions to the Sokal affair in the UK $(2008,126 f f)$. 
Although the two positions might never be meaningfully reconciled, their co-existence can contribute constructively to agonistic learning (Rip 2003, 425) within STS.

\section{Disciplines and Disciplining}

Later in the interview, Stirling questions Michael Lynch and Sheila Jasanoff's efforts to establish STS as a discipline with clearly defined principles, methods of operation, and concepts. He accepts that some "closing down" (Stirling 2008) has enabled the emergence of precise concepts, which he deems unquestionable assets for the field. Yet, he worries that this agenda results from the pressure STS researchers face to build a career within disciplinary institutions. He argues that Lynch's own research demonstrates how efforts to delineate strict modes of operation within STS risk closing STS off from dialogues with external actors who play an important role holding our claims to account. If Lynch is correct to claim that reflexivity is better understood as "communal and relational"--as opposed to "individual and intentional" (Lynch 2000) — then it follows, says Stirling, that we should ensure the field remains open to a plurality of perspectives and approaches. It is better, he suggests, to see STS as a host for ongoing and diverse debates about science, technology, and society.

There is no easy solution to the question of how STS should negotiate its own boundaries —all epistemic boundaries are socially constructed, malleable, and renegotiable (Gieryn 1983). Keeping the field open to different modes of working invites diverse perspectives and framings to shape STS research, while operating in a closed mode enables us to hone a set of distinctive yet transferable concepts and analytical tools that can facilitate STS's "growth" in academic environments. Both are necessary for the field; the challenge is to develop and refine concepts while at the same time being receptive to alternative framings and emerging approaches to understanding the relationship between science, technology, and society. As an early career researcher, I also hope that acting on both imperatives will create greater career opportunities for our graduates.

\section{Riding with Reflexivity}

Divergent perspectives amongst "STSers" are to be expected. We should anticipate different views about what is "acceptable," "credible," "respectable" STS research, and what it means for researchers to "mean business" legitimately (Woolgar, Coopmans and Neyland 2009; Lynch 2009). In the interview we were both surprised when Stirling reached the conclusion that debates such as those discussed above reflect broader disagreements in society, and are therefore probably not reconcilable. It follows that researchers should acknowledge and even embrace the likelihood of ongoing disagreements that reflect wider societal tensions within the field. I

${ }^{4}$ Jasanoff $(2004,3)$ argues that this is a means of expanding STS's reach. 
conclude that this is what it means to be talking STS: to expect to encounter a diversity of views, and to treat as suspicious any claims that differences have been reconciled.

Stirling's charge that there is a loss of nerve in the field played on my mind during the long train ride back to Edinburgh. I asked myself whether I am "critical enough" in my own work. What reason do I have to think that I am? I took comfort in the idea that critique-like reflexivity-must be a distributed property and will arise from debate within the STS community and beyond. Therefore, if I am to confront my insecurities I must engage in open discussions with diverse actors and always be prepared to learn to see the world from multiple perspectives. This seems to be the only thing I can do. Is it enough?

Thinking about the issue more structurally, it follows that quality of debate and plurality of voices participating in those debates should be added to the ways we assess our field's success. Otherwise we risk interpreting the field's dilution as expansion. But then, who gets to decide what validly counts as "quality" and "plurality"?

\section{Author Biography}

Andy Stirling's undergraduate studies at Edinburgh began in astronomy before shifting through science studies to an MSc in archeology and social anthropology. In the 1980s, he worked as a field archaeologist and ecology and peace activist. He went on to co-ordinate the nuclear, disarmament and energy campaigns for Greenpeace International, later serving on national and international Greenpeace boards. Stirling returned to academia to complete a doctorate in science and technology policy at the Science Policy Research Unit at the University of Sussex, where he has worked since 1995 as an interdisciplinary "policy-engaged" researcher. He has wrestled with challenges of empowerment, environment and human wellbeing in the politics of knowledge and innovation, with a key emphasis on efforts to democratize progress. Stirling has had several professional roles including Research Director for SPRU (2006-13) and Deputy Director for the joint Surrey-Sussex Research Group on Sustainable Lifestyles. Over the years, he has also collaborated with a variety of public, business and civil society organizations, serving on several governmental advisory bodies. He is presently seeking to build a non-profit, public interest enterprise to develop and establish a novel tool for "opening up" strategic appraisal, called "multicriteria mapping." $\mathrm{He}$ is currently involved in projects on reframing general concepts of security, understanding energy security, mapping science systems and exploring "responsible innovation." He serves on the Research Committee of the UK's Economic and Social Research Council, and on editorial boards for the Journal of Risk Research, Minerva, Nature, EMBO Reports, Technology Analysis \& Strategic Management and Environment Innovation and Societal Transition.

\section{Author Biography}

Michael Kattirtzi is a UKERC-funded Postdoctoral Researcher in Science, Technology and Innovation Studies at the University of Edinburgh. His current research identifies and explains 
points of agreement and disagreement amongst policy stakeholders and researchers contributing to UK energy policy. He is also a Research Fellow at the UCL Energy Institute, working on a quantitative project exploring the relationship between the use of central heating controls and heating patterns in English dwellings. In 2017, Michael completed his ESRC-funded PhD thesis at the University of Edinburgh, exploring the history of social research influence and capacity within the UK Government's Department for Environment, Food and Rural Affairs, and the Department of Energy and Climate Change. He has recently published his PhD findings in the first Research Handbook on EU Energy Law and Policy, and the Palgrave Communications special collection on Scientific Advice to Governments.

\section{Acknowledgements}

This article would not have been possible without support from the ESRC (Award Grant: ES/J500136/1) and the Science, Technology and Innovation Studies Subject Group at the University of Edinburgh. Thanks to Fadhila Mazanderani and Pablo Schyfter for making this project possible, Isabel Fletcher and Thokozani Kamwendo for their thorough editing work, and of course to Professor Andy Stirling for sharing his reflections with me.

\section{References}

Collins, H. 1996. "In Praise of Futile Gestures." Social Studies of Science, 26(2):229-244.

Collins, H. 2006. "The Science Wars." Cardiff University, Available from: http://www.cardiff.ac.uk/socsi/contactsandpeople/harrycollins/science-wars.html (accessed 18 October 2015).

Collins H. and R. Evans. 2002. "The Third Wave of Science Studies." Social Studies of Science, 32(2):235 -296.

Gieryn, T. F. 1983. "Boundary-Work and the Demarcation of Science from Non-Science: Strains and Interests in Professional Ideologies of Scientists." In American Sociological Review 48(6):781-795.

Gilbert N. and M. Mulkay. 1984. Opening Pandora's Box: A Sociological Analysis of Scientists' Discourse. Cambridge: Cambridge University Press.

Jasanoff, S. 2004. States of Knowledge. London: Routledge.

Kuhn, T. S. 1970. The Structure of Scientific Revolutions. Chicago: University of Chicago Press.

Lock S. J. 2008. Lost in Translations: Discourses, Boundaries and Legitimacy in the Public Understanding of Science in the UK. University College London: PhD Thesis.

Lynch M. 2000. "Against Reflexivity as an Academic Virtue and Source of Privileged Knowledge." Theory, Culture \& Society, 17(3):26-54.

Lynch, M. 2009. "Science as a Vacation: Deficits, Surfeits, PUSS, and Doing Your Own Job." Organization, 16(1):101-119.

Popper, K. 1959. The Logic of Scientific Discovery. London: Hutchinson.

Rip, A. 2003. "Constructing Expertise." In Social Studies of Science 33(3):419-434. 
Stirling, A. 2006. "Precaution, Foresight and Sustainability." In Reflexive Governance for Sustainable Development, edited by J. P. Voss, D. Baucknecht, and R. Kemp, 225-272. Chelternham: Edward Elgar Publishing.

Stirling, A. 2007. "Risk, Precaution and Science: Towards A More Constructive Policy Debate: Talking Point On The Precautionary Principle." In EMBO Reports 8(4):309-315.

Stirling, A. 2008. "'Opening Up' and 'Closing Down': Power, Participation, and Pluralism in the Social Appraisal of Technology." Science, Technology and Human Values 33(2):262-294.

Stirling, A. and S. Mayer. 1999. Rethinking Risk: A Pilot Multicriteria Mapping of a Genetically Modified Crop in Agricultural Systems in the UK. University of Sussex: SPRU.

Woolgar, S., C. Coopmans and D. Neyland. 2009. “Does STS mean business?” Organization 16(1):5-30.

Yearley, S. 2005. Making Sense of Science. London: Sage. 